\title{
DeBanda e a máquina contemporânea
}

\section{Debanda and the contemporary machine}

\author{
João Lucas ${ }^{1}$ \\ César Lignelli ${ }^{2}$
}

\begin{abstract}
Resumo
Os autores versam acerca do experimento estético colaborativo DeBanda com foco em suas interfaces técnicas e tecnológicas. Para tal, são expostos e problematizados fluxos e embates entre instâncias maquínicas e orgânicas do processo. A experiência teve seu início em 2015 no âmbito do Grupo de Pesquisa Vocalidade \& Cena $(\mathrm{CNPq})$ e envolve a participação de quatro professores do CEN-UnB e dois discentes do PPG-Arte-UnB. Até o momento, esteve em Singapura e circulou por seis países da América do Sul, que resultaram em material para um catálogo bilíngue, 65 pinturas e desenhos e um documentário longa metragem que se encontra em finalização.
\end{abstract}

\section{Palavras-chave}

Colaboração; performance; máquina; tecnologia; técnica.

\begin{abstract}
The authors discuss DeBanda's aestheticcollaborative experiment with a focus on its technical and technological interfaces. For this, flows and clashes between machinic and organic instances of the process are exposed and problematized. The experiment began in 2015 within the Research group Vocalidade \& Cena (CNPq) and involves the participation of four teachers from CEN-UnB and two students from PPG-Arte-UnB. So far, it has been in Singapore and circulated in six South American countries, which resulted in material for a bilingual catalog, 65 paintings and drawings, and a documentary feature film that is in the making.
\end{abstract}

\section{Keywords}

Collaboration; performance; machine; technology; technical.

\footnotetext{
${ }^{1}$ João Paulo Lucas é pianista, compositor e pesquisador. Colaborou com alguns dos mais importantes criadores do teatro e da dança contemporânea em Portugal, tendo participado como compositor em mais de setenta peças, muitas delas premiadas nacional e internacionalmente. Radicado em Brasília desde 2010, é mestre em Artes pela Universidade de Brasília, na linha de pesquisa de Processos Composicionais para a Cena. E-mail: joaolucasmusic@gmail.com

${ }^{2}$ César Lignelli é professor de Voz e Performance do Departamento Artes Cênicas (CEN) e do Programa de Pós-Graduação em Artes Cênicas (PPG-CEN) da Universidade de Brasília. PósDoutor pelo Programa Avançado de Cultura Contemporânea da Universidade Federal do Rio de Janeiro. É Doutor em Educação e Comunicação, FE/UnB; Mestre em Arte e Tecnologia IDA/UnB; Líder do Grupo de Pesquisa Vocalidade \& Cena (CNPq). Pesquisa e orienta temas que envolvam sonoridades, estéticas e pedagogias. Email: cesarlignelli@gmail.com
} 
SerBanda é uma máquina que produz música, reunindo num só dispositivo o controle de uma multiplicidade de instrumentos musicais, acionados por um único operador. A partir dessa máquina se edifica um contexto expansivo de composição performativa que irá proporcionar o objeto problematizado nestas linhas: o processo criativo de um espetáculo de rua que flexibiliza a fixação de gênero vinculada convencionalmente a este conjunto de instrumentos, organizados e tocados por uma mesma pessoa. De pendor drasticamente artesanal, a máquina SerBanda distorce tal atributo quando observada no território mais vasto da sua implicação com a contemporaneidade, perturbação implícita no diálogo entre a tradição centenária do jogral e o desafio hipertecnológico omnipresente na nossa sociedade de informação. É desígnio deste texto pensar a tecnologia envolvida nessa curvatura conceitual, desdobrando tal pensamento na heterogeneidade das instancias em que se desvela. Dizem-nos os dicionários que o significado de Tecnologia se aplica a uma ciência cujo objeto é a aplicação do conhecimento técnico e científico para fins industriais e comerciais, ou ao conjunto dos termos técnicos de uma arte ou de uma ciência, ou ainda ao Tratado das artes em geral. Falemos, pois, das artes em geral, que neste caso nos lança na interrogação do fazer, uma interrogação futurista no mundo da alta tecnologia, da tecnologia de ponta, da tecnologia da informação, da tecnologia dos circuitos integrados que ressoa no tamborilar de dedos que teclam, da tecnologia de autômatos infalíveis que apagam da memória a pele, os ossos, a carnadura e as fibras nervosas de um homem exonerado do mundo pela sua própria espécie.

SerBanda é uma máquina futurista porque resgata algo que já só faz sentido na arte. Como máquina evoca permanentemente a obsolescência da sua própria natureza, a marca da mão, a nostalgia do engenho, o atrito do excesso e o malogro do rigor. Mas como aparato de expressão, ele afirma o que as mais altas tecnologias calam, porque as altas tecnologias aderem ao seu tempo, produzem-no, mas não se dissociam dele nem o observam. A máquina SerBanda conquista nesse vislumbre a sua contemporaneidade, porque se inscreve no tecido do presente tecendo-o com os fios do arcaico e ao fazê-lo desafia a atualização do gesto tecnológico com a exposição do seu devir histórico e a evidencia do seu propósito pri153 
mordial. Como refere Giorgio Agamben, "a distância - e, ao mesmo tempo, a proximidade - que define a contemporaneidade tem o seu fundamento nessa proximidade com a origem, que em nenhum ponto pulsa com mais força do que no presente" (2009: 69).

O labirinto de dezenas de metros de cordões e cabos de aço de diferentes espessuras, centenas de parafusos, ruelas e porcas, mãos francesas de tamanhos variados, passadores de corda, abraçadeiras de plástico e de metal, ganchos, fivelas, fechos e prolongadores diversos, pedaços de madeira, ferragens de bateria, espuma, rolos de fita de alta fusão, colas adesivas, fitas adesivas, fita de lona de caminhão, fibra acrílica de enchimento, tinta de tecido, carrinho de compras e mochila dão liga a um tambor de cabaça, um tamborim, dois reco-recos, um pedal duplo de bateria, um prato, um bumbo, duas claves cubanas, uma campainha de hotel antigo, três buzinas a ar, dois agogôs, um kazoo, uma surdina de trompete, nove apitos, seis baquetas sendo duas luminosas e uma com sete hastes de nylon enfeixadas, mais duas próteses de braços humanos ergue uma máquina tocável de aproximadamente $30 \mathrm{~kg}$ cujo desígnio principal é o prolongamento do tocador e a multiplicação das suas virtualidades sônicas, mas igualmente a visibilidade dessas virtualidades e a sonoridade da atualização do corpo por ela agenciada. Corpo e máquina tendem entre si reciprocamente e nessa convergência consumam sua aparição bifurcada numa maquinaria humana e numa humanidade maquínica, implicadas num devir indissociável. O seu acoplamento produzirá um fluxo solidário que expressa um desejo dual, o desejo do corpo por uma expressão maquínica e o desejo da máquina pela vitalidade humana. Tocador e SerBanda são máquinas desejantes que se convertem num organismo (ver figuras 1 a 4 ). 
VIS

Revista do Programa de Pós-graduação em Arte da UnB

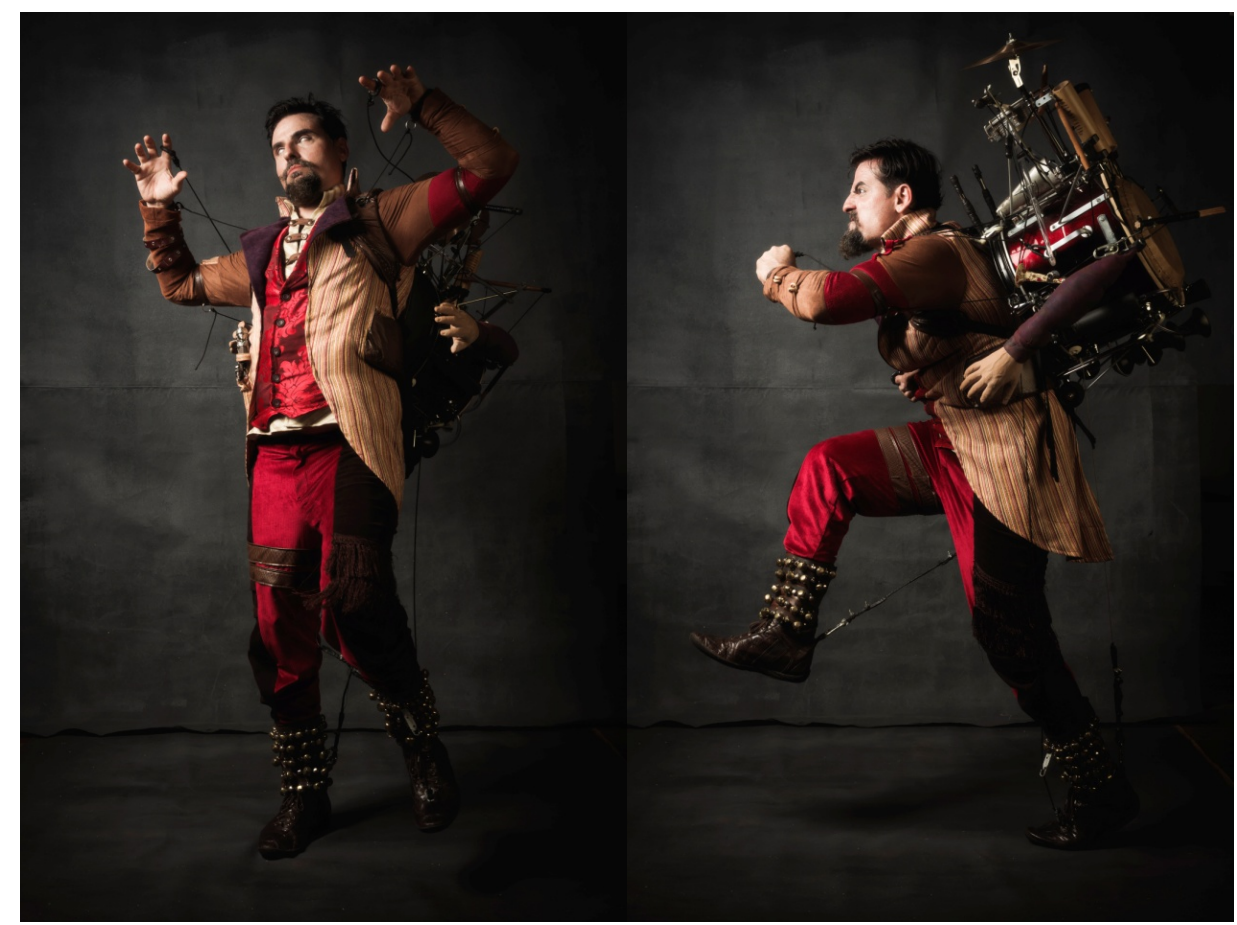

Figura $1^{3}$

Figura 2

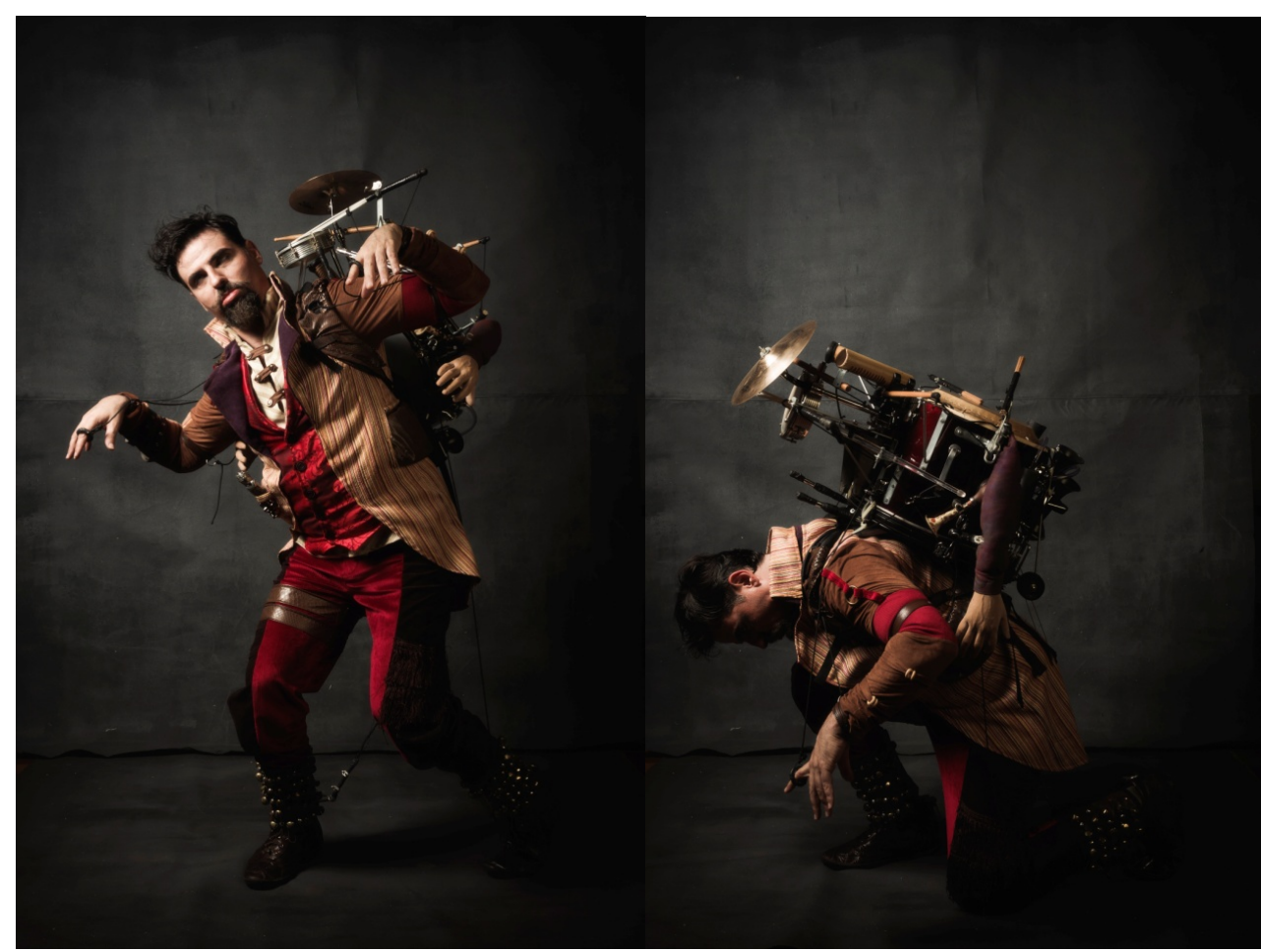

Figura 3

Figura 4

${ }^{3}$ Fotos 1 a 4 de Diego Bresani. Máquinas desejantes: tocador (César Lignelli) e SerBanda. 
Os dois pertencem-se, SerBanda nasceu do engenho e do labor do artesão que toca, o tocador que o fez vai nascendo num movimento de osmose com a sua criatura, enfrentando o emaranhado das suas armadilhas funcionais, rendendo as suas insubordinações intempestivas, refazendo carinhosamente circuitos imperfeitos, recondicionando lenta e continuamente o seu metabolismo. A produção de presença deste corpo binário é uma duração arriscada no fracasso e embriagada no desejo. Fracasso e desejo são o seu idioma.

\section{A máquina dramatúrgica}

Esse idioma cria a própria engrenagem, gerando a célula embrionária que deflagrará um novo mecanismo. Uma engrenagem de palavras, imagens e representações em deriva associativa, juntando ideias dispersas num torvelinho de sentidos. O tocador expele a sua imanência performativa sob a forma de possibilidades de substancialização e estas se fundamentam no erguer da sua própria circunstância. Quem é este ser ambíguo, que range as suas juntas sinfônicas e que almeja o coração dos incautos? A máquina dramatúrgica produz seus primeiros oráculos sob a forma de um solido platônico, num desdobramento piramidal. Na base, um triângulo delimita a área de tensões fundamentais que polarizam as pulsões do desejo. Um triângulo amoroso, competente para acionar os êmbolos da paixão, as manivelas do ciúme, com válvulas de escape para a sedução e para o despeito, com fluxos hidráulicos por onde se escoa a libido e circuitos tubulares para resfriamento de combustões excessivas, com correias dentadas que movimentam dramaticamente os desencontros e fluidos viscosos que lubrificam o transito das pulsões. Do vértice superior desta pirâmide nos chega a voz do jogral, desde logo crismado com uma referência direta à máquina que o completa: DeBanda é o narrador, o mensageiro, o Corifeu, fazendo deslizar pelas arestas da pirâmide os fios condutores que o ligam aos três vértices restantes, pontuando geometricamente os demais personagens. Para estes foi criado um contexto sumário, uma paixão de $\mathrm{A}$ por B tumultuada por C. A alavanca dramatúrgica acionou então um braço coletor que colocou As Cosmicômicas de Ítalo Calvino em circulação no plano de imanência das virtualidades triangulares: 
Admitindo-se, portanto, que caíssemos, caíamos todos com a mesma velocidade sem qualquer impedimento; de fato estávamos sempre, a bem dizer, na mesma altura, eu, Úrsula H'x, o tenente Fenimore. Não tirava os olhos de cima de Úrsula H'x porque era muito bonita de se ver, e mantinha na queda uma atitude ágil e descontraída: esperava conseguir alguma vez interceptar o seu olhar, mas Ursula H'x, ao cair, estava sempre ocupada em lixar e polir as unhas ou em passar o pente nos cabelos longos e lisos, e jamais voltava o olhar para mim. Para o tenente Fenimore tampouco, devo dizer, muito embora ele fizesse tudo para atrair sua atenção (1992: 116).

Atravessando um fino sistema de filtragem, estes personagens foram sendo expurgados da sua consistência romanesca original, depositando sedimentos impressivos sobre a projeção mental dos nossos três personagens, das latências dramáticas da sua implicação e das potencialidades performativas dos seus contrastes. As palavras e a sua engrenagem significante criavam conexões inventivas no território ainda elementar do dispositivo dramatúrgico. Dois homens - Demenos e Demais - e uma mulher - Ella - receberiam deste texto a sua ignição vital, emergindo, com seus semblantes gasosos, no caldo de cultura de uma narrativa ainda desprovida de matéria. Vibravam já intensidades impressivas que sinalizavam a vitalização de um porvir para a máquina DeBanda. Foi então que borbulhando, DeBanda além da simbiose já realizada, em função de seus devires empunhou duas gaitas de ponto, uma replica de pistola do século XIX e um laço feito de conduite que complementariam a sonoridade e a caracterização daqueles que germinavam.

\begin{abstract}
Não se perguntará nunca o que um livro quer dizer, significado ou significante, não se buscará nada compreender num livro, perguntar-se-á com o que ele funciona, em conexão com o que ele faz ou não passar intensidades, em que multiplicidades ele se introduz e metamorfoseia a sua, com que corpos sem órgãos ele faz convergir o seu. Um livro existe apenas pelo fora e no fora. Assim, sendo o próprio livro uma pequena máquina, que relação, por sua vez mensurável, esta máquina literária entretém com uma máquina de guerra, uma máquina de amor, uma máquina revolucionária etc. - e com uma máquina abstrata que as arrasta (Deleuze; Guattari, 2000: 11).
\end{abstract}

Inaugurado o sistema de conexões referenciais, o braço coletor extraiu a extravagância do personagem Peepercorn, à Montanha Mágica de Thomas Mann, 
VIS

Revista do Programa de Pós-graduação em Arte da UnB

moldando a quente o voluntarismo quixotesco de Demenos. Ella sofreu uma centrifugação entre elementos heterogêneos, combinando o canto das sereias de Homero com a Lolita de Nabokov, o erotismo de Bardot e a perversidade de Medusa, originando uma liga singular de alto teor abrasivo. O tenente Fenimore foi, por sua vez, enriquecido com D. Juan de Byron, com o Fausto de Goethe e o Bel Ami de Maupassant, atingindo uma irradiação dramática autocomburente, capaz de aniquilar a mais resistente estabilidade entre polaridades erotizadas.

Há ainda a difusa sombra dos personagens, percebida no cruzamento entre estas procedências romanescas, que é interligada por uma rede de circuitos integrados que vai depositando, em cada um, atributos suplementares heterogêneos, lubrificando o processo de expansão das suas representações e cartografando as funcionalidades dramatúrgicas que se irão articular na combustão narrativa. Estes atributos organizam-se, por sua vez, como elos da corrente de transmissão que irá transmitir a potência dos personagens à planificação do seu movimento dramático. À imagem de elementos químicos de uma tabela periódica, funções, características, desejos, estratégias, vulnerabilidades, adereços, objetivos, dispositivos e interlocução irão produzir as transfigurações adequadas à constituição de diferentes reações passionais no destino dos protagonistas (ver figura 5). 


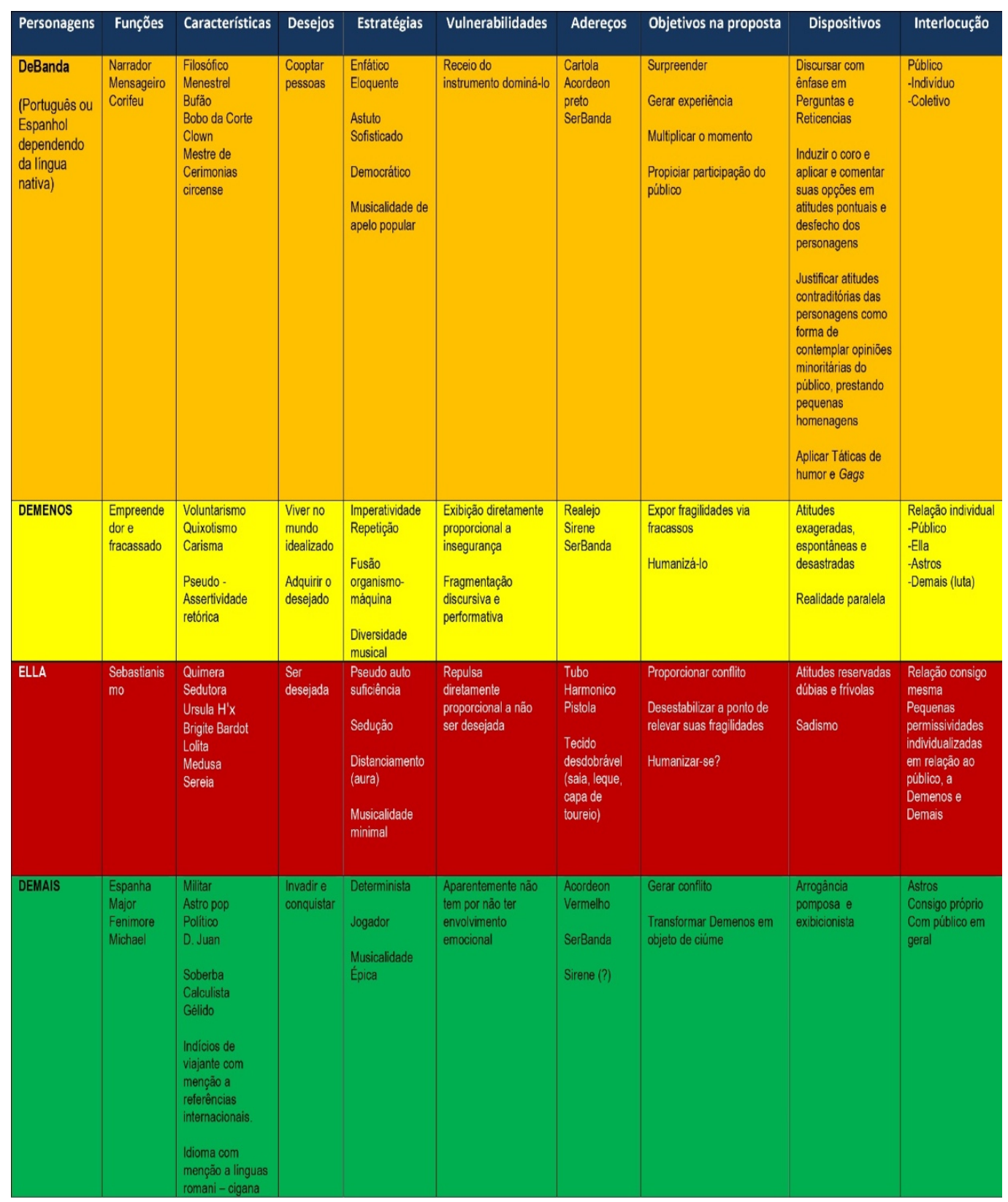

Figura 5. Tabela de atributos dos personagens. César Lignelli e João Lucas.

A organização temporal deste canovaccio $^{4}$ será objeto de outra diagramação, destinada a distribuir as funções motóricas das ações no trilho da narrativa.

${ }^{4}$ Canovaccio (termo italiano que advém de canapa, 'cânhamo', através do francês canevas, 'tecido grosso'), indica alguns elementos básicos da trama de um evento estético, apontando de maneira genérica seu desenvolvimento. Este recurso já era utilizado entre os séculos XVI e XVIII pela comedia Del Arte e continha, em linhas gerais, o tema, a descrição das situações e as personagens intervenientes (N.doA.). 
Referimo-nos ao guião, outro eixo central da engrenagem dramatúrgica cuja rotação incide, agora, sobre a torção engrenada de causas e efeitos na deriva novelesca entre os vários componentes. Responsável pela injeção de pontos de ancoragem no enredo, a partir dos quais basculam algumas possibilidades abertas ao arbítrio do público, posiciona-se DeBanda, ora mediando as peculiaridades das personagens como um alternador que converte a energia performativa em devir dramatúrgico, ora misturando adequadamente exalações dramáticas como um carburador alquímico alimentador de combustões fatais. Neste campo induzido de polaridades alternativas, a plateia concorre para o direcionamento dos destinos dos personagens, funcionando como uma espécie de termostato que regula o movimento macroestrutural de pressões, tensões e relaxamentos, controlando parcialmente os seus atritos e as suas confluências. Esta engrenagem organiza-se por blocos de apresentação dos personagens e momentos de conexão ou de hostilidade entre eles (distinguindo-se uma secção inicial enunciadora e uma secção final conclusiva), sendo a sua triangular implicação equilibrada por uma matriz geradora de proporcionalidade, elaborada a partir da série de Fibonacci (ver figura 6).

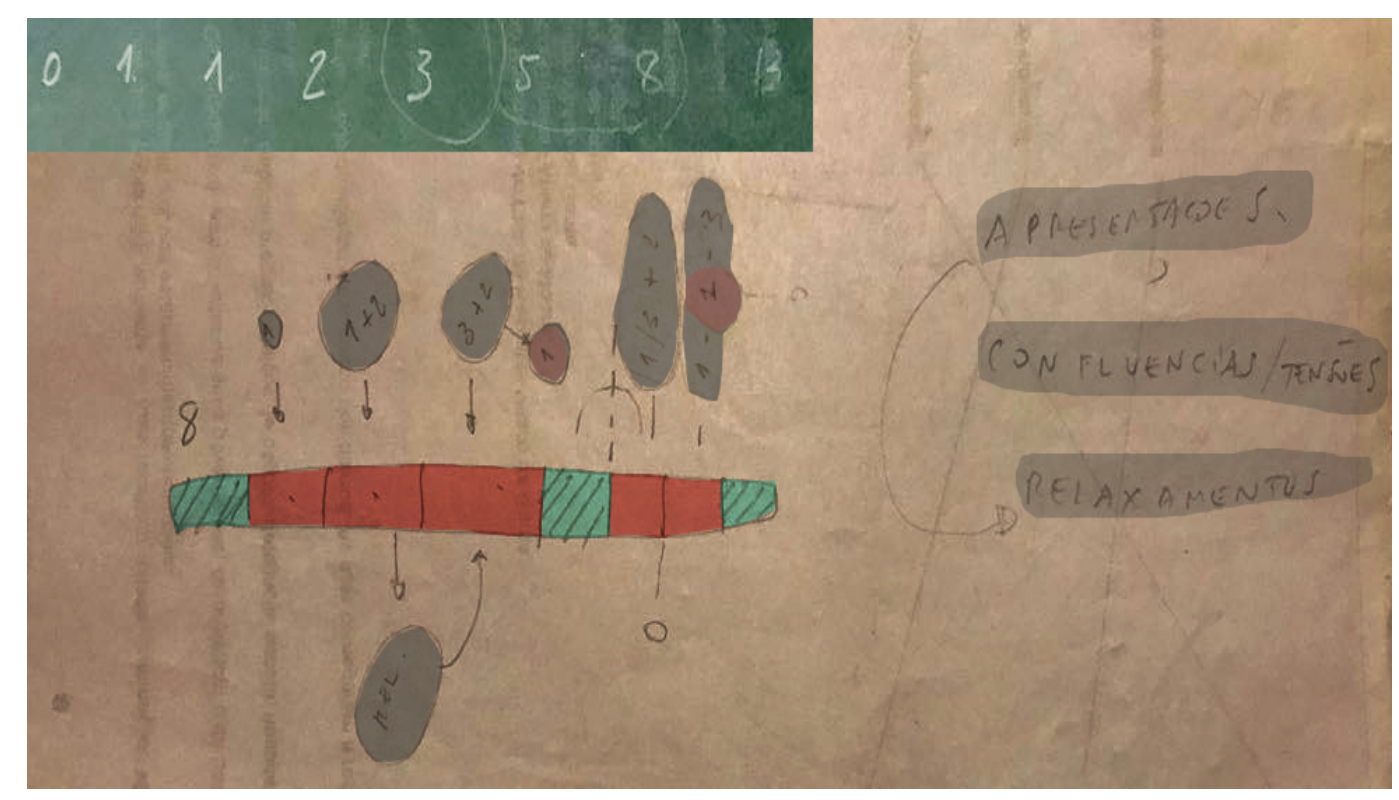

Figura 6. Esboço da organização dramatúrgica macroestrutural. João Lucas.

DeBanda, anfitrião, narrador e catalisador de reações entre a teia interativa de eventos e a presença performativa do público, protagoniza três pontos chave da 160 
VIS

Revista do Programa de Pós-graduação em Arte da UnB

cadeia de eventos, introduzindo a trama, promovendo o debate central sobre o seu desenlace e rematando a performance diluindo-se nela, arrastando nesse gesto a condensação dos restantes protagonistas.

Sobre este delineamento esquemático desdobram-se distintas unidades funcionais, dando expressão, quer à exposição dos traços identificadores dos componentes dramatúrgicos, quer à sua interação produtiva. Trata-se de diferentes segmentos musicais compostos em função das características performativas de cada personagem e das intensidades de cada encadeamento narrativo:
1. Cortejo
2. Regras
3. Demenos
4. Ella
5. Êxtase do sim.
6. Demais
7. Ella+Demais
8. Lamento
9. Desenlace
10. Despedida

Cada um destes segmentos irá, por sua vez, desdobrar-se em diferentes esferas de funcionalidade performativa, alinhando, por um lado, as ranhuras dos gestos composicionais nos sulcos correspondentes às diferentes áreas expressivas e lubrificando, por outro, a consistência virtual da interligação entre componentes dramáticos, cinéticos e sonoros (ver figura 7). 


\begin{tabular}{|c|c|c|c|c|c|c|c|}
\hline Cannovaccio & Função & Personagens & Ação & $\begin{array}{c}\text { Movimento } \\
\text { dramatúrgico }\end{array}$ & $\begin{array}{l}\text { Material } \\
\text { Cinético }\end{array}$ & Percurso Espacial & Material Sonoro \\
\hline 1a & Cortejo & deBanda & Convocar público & $\begin{array}{l}\text { Despertar } \\
\text { desejo }\end{array}$ & $\begin{array}{l}\text { Marcação do } \\
\text { tempo com os } \\
\text { pés e giros } \\
\text { Acompanhamento } \\
\text { do deslocamento } \\
\text { do público } \\
\text { Instabilidade } \\
\text { controlada }\end{array}$ & Arena expandida & Canção Cortejo - Ac Preto.Bd.Sd \\
\hline $1 \mathrm{~b}$ & Regras & deBanda & $\begin{array}{l}\text { Expor regras e } \\
\text { adquirir premissas }\end{array}$ & \begin{tabular}{|l|} 
Preparar e \\
propiciar a \\
narrativa \\
pseudo-coletiva
\end{tabular} & $\begin{array}{l}\text { Foco direcionado } \\
\text { sem constranger }\end{array}$ & Arena delimatada & Caráter improvisatório- Ac Preto \\
\hline 2 & Apresentação & Demenos & $\begin{array}{l}\text { Cativar e } \\
\text { empolgar o } \\
\text { público indicando } \\
\text { açōes } \\
\text { Ponderacōes } \\
\text { filosóficas }\end{array}$ & $\begin{array}{l}\text { Apresentar e } \\
\text { expor o caráter } \\
\text { contraditório, } \\
\text { proativo e } \\
\text { megalomano }\end{array}$ & $\begin{array}{l}\text { Movimentos } \\
\text { entrecortados, } \\
\text { diretos, } \\
\text { controlados ao } \\
\text { extremo para dar } \\
\text { a sensação de } \\
\text { espasmódicos }\end{array}$ & $\begin{array}{l}\text { Tangenciar circularmente o público } \\
\text { Movimentação centrifuga e } \\
\text { centripeta } \\
\text { Circular sobre si } \\
\text { Percurso termina na posição inicial }\end{array}$ & Melodia continua com SerBanda \\
\hline $2 a$ & Reação/Aparição & $\begin{array}{l}\text { Demenost } \\
\text { Ella virtual }\end{array}$ & $\begin{array}{l}\text { Mudança do } \\
\text { público para Ella }\end{array}$ & $\begin{array}{l}\text { Evidenciar sua } \\
\text { paixăo } \\
\text { tresloucada a } \\
\text { primeira vista } \\
\text { por Ella }\end{array}$ & Passos & $\begin{array}{l}\text { Tangente ao trailer na direção da } \\
\text { outra extremidade. Pelo caminho } \\
\text { troca de pele. }\end{array}$ & Apitos do SerBanda \\
\hline 3 & Apresentação & Ella & Seduzir o público & $\begin{array}{l}\text { Criar objeto de } \\
\text { desejo }\end{array}$ & $\begin{array}{l}\text { Ondulação- } \\
\text { ancas e mãos, } \\
\text { desenho ritmico } \\
\text { da arma e } \\
\text { movimento } \\
\text { circular do tubo } \\
\text { harmonico } \\
\text { Passos minimos }\end{array}$ & $\begin{array}{l}\text { Inicio na extremidade esquerda } \\
\text { Percurso triangular }\end{array}$ & $\begin{array}{l}\text { Cantiga esparsa/Ella } \\
\text { Tubo harmônico e pistola rítmica - } \\
\text { Suspensão do serBanda (residual) }\end{array}$ \\
\hline $3 \mathbf{b}$ & $\begin{array}{l}\text { Relação } \\
\text { amorosa }\end{array}$ & Demenos/Ella & $\begin{array}{l}\text { Dançar uma valsa } \\
\text { em uma corte... }\end{array}$ & $\begin{array}{l}\text { Passagem do } \\
\text { tempoe } \\
\text { intensidade da } \\
\text { relação }\end{array}$ & $\begin{array}{l}\text { Leveza e corpo } \\
\text { rodopiante } \\
\text { alternando os } \\
\text { personagens }\end{array}$ & Circular e velocidade crescente & Sanfona vermelha \\
\hline $4 a$ & Apresentação & Demais & $\begin{array}{l}\text { Imposiçāo de } \\
\text { magnitude }\end{array}$ & $\begin{array}{l}\text { Desestabilizar a } \\
\text { empatia do } \\
\text { público gerada } \\
\text { pela história } \\
\text { amorosa }\end{array}$ & \begin{tabular}{|l} 
Dança da \\
sedução do \\
ladrão - menção \\
a culturas várias e \\
distantes
\end{tabular} & $\begin{array}{l}\text { Estrutura de Losango e circular } \\
\text { Contraste do refrão em cámera } \\
\text { lenta. }\end{array}$ & $\begin{array}{l}\text { Canção Épica } \\
\text { Ac. Vermelho }\end{array}$ \\
\hline $4 \mathrm{~b}$ & $\begin{array}{l}\text { Reação a } \\
\text { Demais }\end{array}$ & Ella+Demais & $\begin{array}{l}\text { Sinaliza como } \\
\text { revolver a ruptura } \\
\text { com Demenos }\end{array}$ & $\begin{array}{l}\text { Evidenciar sua } \\
\text { paixão } \\
\text { tresloucada a } \\
\text { primeira vista } \\
\text { por Demais }\end{array}$ & $\begin{array}{l}\text { desenho ritmico } \\
\text { da arma e } \\
\text { movimento } \\
\text { circular do tubo } \\
\text { harmónico }\end{array}$ & Percurso espacial quase estático & Tubo hamônico e pistola ritmica \\
\hline 4C & Lamento & Demenos & $\begin{array}{l}\text { Lamentar a } \\
\text { possibilidade de } \\
\text { perda }\end{array}$ & $\begin{array}{l}\text { Exposiçâo da } \\
\text { dor do herói } \\
\text { trágico }\end{array}$ & $\begin{array}{l}\text { Giro da manivela } \\
\text { do Realejo }\end{array}$ & Prostração & $\begin{array}{l}\text { Cançāo lamento I } \\
\text { Realejo }\end{array}$ \\
\hline 5 & $\begin{array}{l}\text { Exposiçăo dos } \\
\text { fatos, julgamento } \\
\text { e desenlace }\end{array}$ & DeBanda & $\begin{array}{l}\text { Inquirição ao } \\
\text { público }\end{array}$ & $\begin{array}{l}\text { Criaçāo de } \\
\text { Tensão } \\
\text { VIRADA }\end{array}$ & $\begin{array}{l}\text { Encarar o püblico } \\
\text { Iniveis Laban e } \\
\text { por vezes a } \\
\text { pergunta è para } \\
\text { os céus.. } \\
\text { TRIBUNAL } \\
\text { PLENÁRIO }\end{array}$ & & $\begin{array}{l}\text { forró multitonal } \\
\text { vermelho vibratório }\end{array}$ \\
\hline
\end{tabular}

Figura 7. Guião diagramático. César Lignelli e João Lucas.

Pode-se, por fim, entender um amplo movimento indutor de sentidos e relações significantes que conecta a tabela de atributos com o guião, passando por impulsos intermédios de estruturação parcial, estabilizando nesse transito toda a sorte de lampejos inventivos e explosões metafóricas que vão proliferando ao longo do processo de criação. Este movimento e a sua consequência diagramática em refinamento contínuo é agenciado por um dispositivo dramatúrgico. O dispositivo dramatúrgico surge no prolongamento genealógico da expansão conceitual de dramaturgia, abrindo-se à invenção de zonas de contato, sobreposição, torção ou desdobramento entre os objetos dramáticos, performativos, coreográficos e musi162 
cais, acionando os seus os conectores e virtualizando os seus nexos. Nesse aspecto, aproxima-se da máquina abstrata de Deleuze, uma máquina de mutação que opera por descodificação e desterritorialização.

\begin{abstract}
As máquinas abstratas consistem em matérias não formadas e funções não formais. Cada máquina abstrata é um conjunto consolidado de matérias-funções (phylum e diagrama). Isto se vê claramente num "plano" tecnológico: um tal plano não é composto simplesmente por substâncias formadas, alumínio, plástico, fio elétrico, etc, nem por formas organizadoras, programa, protótipos, etc, mas por um conjunto de matérias não formadas que só apresentam graus de intensidade (resistência, condutibilidade, aquecimento, estiramento, velocidade ou retardamento, indução, transdução...), e funções diagramáticas que só apresentam equações diferenciais ou, mais geralmente, "tensores". Certamente, no seio das dimensões do agenciamento, a máquina abstrata ou máquinas abstratas efetuam-se em formas e substâncias, com estados de liberdade variáveis (1997: 227).
\end{abstract}

O dispositivo dramatúrgico não representa apenas a obra, mas o agenciamento da implicação e da temporalidade dos objetos que orientam o esforço composicional, configurando um conjunto de engrenagens que regula o sistema de acoplamento entre a inventividade cognitiva dos compositores e a substância inventada da composição.

\title{
A máquina colaborativa
}

Todas estas conexões, desdobramentos e acoplamentos semânticos derivam da edificação de uma infraestrutura criativa bipolarizada. A criação de DeBanda é um longo percurso de intersecção criativa de dois núcleos autorais (doravante identificáveis pelas siglas A1 e A2), convergindo em suas identidades expressivas e delineando um mecanismo que se confunde com o próprio processo criativo, mas que não se esgota nele, porque produz um movimento específico de alteridade composicional. Tal alteridade resulta de um processo de desterritorialização progressiva de cada um dos criadores em relação a códigos identitários de concepção e produção do seu respectivo universo criativo. É na experiência da colaboração que, em temperaturas extremas, se forja um peculiar teatro do mundo, cunhado na apreensão que dele fazem os seus sujeitos cognoscentes, não só en- 
quanto espectadores das coisas representadas e enquanto atores potenciais sobre as coisas imaginadas, mas também enquanto sensores sensíveis ao outro, ou como termo acumuladores do que do outro pode ser vivido e incorporado. Aqui podemos constatar o silencioso murmúrio do motor da colaboração, vibrando no rosto do outro.

O regime semanal de encontros entre os autores imprime no sistema motor desse movimento uma pulsação periódica, estabelecendo o ritmo que sinaliza sua lenta transformação no quadro do processo criativo. À permutação de implicações simbólicas entre imagens, sons e palavras em rotação constante na invenção dos autores, vai-se juntando o desvelamento de uma nova potência propulsora: o rosto do outro, "silhueta no horizonte luminoso que não adquire significação a não ser por esta presença ao horizonte. O rosto significa outramente" (Lévinas, 2004: 32). DeBanda acena nesse horizonte, e sem deixar de o contemplar, os seus autores contemplam também o rosto um do outro, aceitando, para lá das representações metodicamente organizadas pelos dispositivos de estabilização dramatúrgica, a trepidação do reconhecimento de significados desalinhados, de interpretações deficitárias, de potencialidades insuspeitadas ocultas no circuito do aparelho circulatório da colaboração, fluindo e sobrando entre representações e conectividades significantes. A convergência gradual que a máquina colaborativa processa na inventividade compositiva dos seus autores decorre desse aparato pré-verbal, prérepresentacional, corporal e pulsional - que gera percepções conscientes, préconscientes e até inconscientes - capacitado para a preensão de emoções e intuições extraídas do rosto do outro, à medida que a própria obra vai ganhando a sua substancia virtual em intuição partilhada na experiência de colaboração.

O rosto é a própria identidade de um ser. Ele se manifesta aí a partir dele mesmo, sem conceito. A presença sensível deste casto pedaço de pele, com testa, nariz, olhos, boca, não é signo que permita remontar ao significado, nem máscara que o dissimula. A presença sensível, aqui, se dessensibiliza para deixar surgir diretamente aquele que não se refere senão a si, o idêntico (Lévinas, 2004: 59). 
A abertura ao rosto do outro é o indutor de alteridade irredutível, que transforma os dois colaboradores através da ignição desveladora de um mundo intersubjetivo, apropriado pela experiência de colaboração; um indutor que, através de lentes divergentes, dispara feixes de intensidade capazes de ultrapassar as fronteiras da razão dialógica, na substancialidade do espaço e na construção do tempo, na totalidade da experiência. Assim, a máquina colaborativa imprime no processo criativo uma dinâmica produzida no movimento do tempo, que regula a exposição empírica de uma entidade plural (intersubjetiva) a uma vivencia sensível comum e que catalisa o rendimento de uma afirmação igualmente comum "O rosto que me olha me afirma" (Lévinas, 2004: 61). Trata-se se um gigantesco obturador cuja abertura se vai expandindo a cada novo encontro, revelando gradualmente os traços identitários de DeBanda - que já não respeitam apenas ao desejo expressivo e à habilidade específica de cada núcleo criador, antes se confundindo com os rastos da presença do outro no processo criativo e com a imagem que o outro projeta na própria antecipação da obra. A1 e A2, originalmente dissociados nas suas competências individuais, carburam agora conjuntamente idealidades voláteis que se expandem a todos os domínios da criação. Presença performativa, desenho de movimento, identidade musical, universo poético, em todos os planos se gera espontânea e sistematicamente uma proatividade orgânica, ocorrência que deriva da aglutinação eletromagnética produzida pelo dínamo de alteridade.

Esta complexa engrenagem adere ao seu próprio movimento, impremeditável e imponderável. Na máquina colaborativa DeBanda, a proposição de uma matéria compositiva é, para o criador que a propõe, uma pegada no caminho da experiência. Um passo certeiro ou um passo em falso, um passo cuja incerta produtividade reside na convicção da coerência ou da intensidade e no assumir do risco de irrelevância ou de impertinência. Antes dessa andança, a máquina desfragmentou sentidos articulados - movimento agenciado pelo dispositivo dramatúrgico - e identificou o rosto do outro - integrou percepções, afecções e intuições em figuras de consciência que sinalizam, de A1 para A2, a relevância deste aventuroso movimento de proposição. Essa proposição passa a ser, por sua vez, uma nova imanência em DeBanda, um novo elo de implicação, talvez uma nova per165 
VIS

Revista do Programa de Pós-graduação em Arte da UnB

cepção ou um novo afeto, uma intensidade, talvez um efeito de presença. Assim foram surgindo matérias heterogêneas, novos instrumentos, novas letras e novas músicas, novos desenhos de movimento e novas causalidades performativas.

Nesse momento de precipitação de novas matéria primas sobre matrizes em progresso (de proclamação de possibilidades que recalculam o direcionamento da obra e que reconfiguram o seu horizonte), a máquina colaborativa transformou os seus sujeitos, o que exprimiu e o que percebeu (ou sentiu) o expresso, seu sentido ou sua intensidade - o que olhou o rosto do outro. A matéria composta $(m c)$ formulada quer por A1, quer por A2, é centrifugada pela experiência em novas articulações de sentido por um e por outro sujeito, cujos gestos de composição se vão articulando com as outras ações dialógicas num duplo movimento - de A1 para A2 e de A2 para A1 - e nessa articulação se desvelando A1 aos olhos de A2. O autor A1 é então sujeito empírico da composição de matéria $(\mathrm{cm})$ - no sentido em que se encontra exposto a ela - e da experiência de desvelamento do autor A2, assim como este é sujeito das experiências da composição e do desvelamento do autor A1. A1 e A2 sujeitam-se assim a uma experiência dual que se abre, por um lado, à matéria da composição e, por outro, ao desvelamento da identidade expressiva (de A1ou de A2) (ver figura 8).

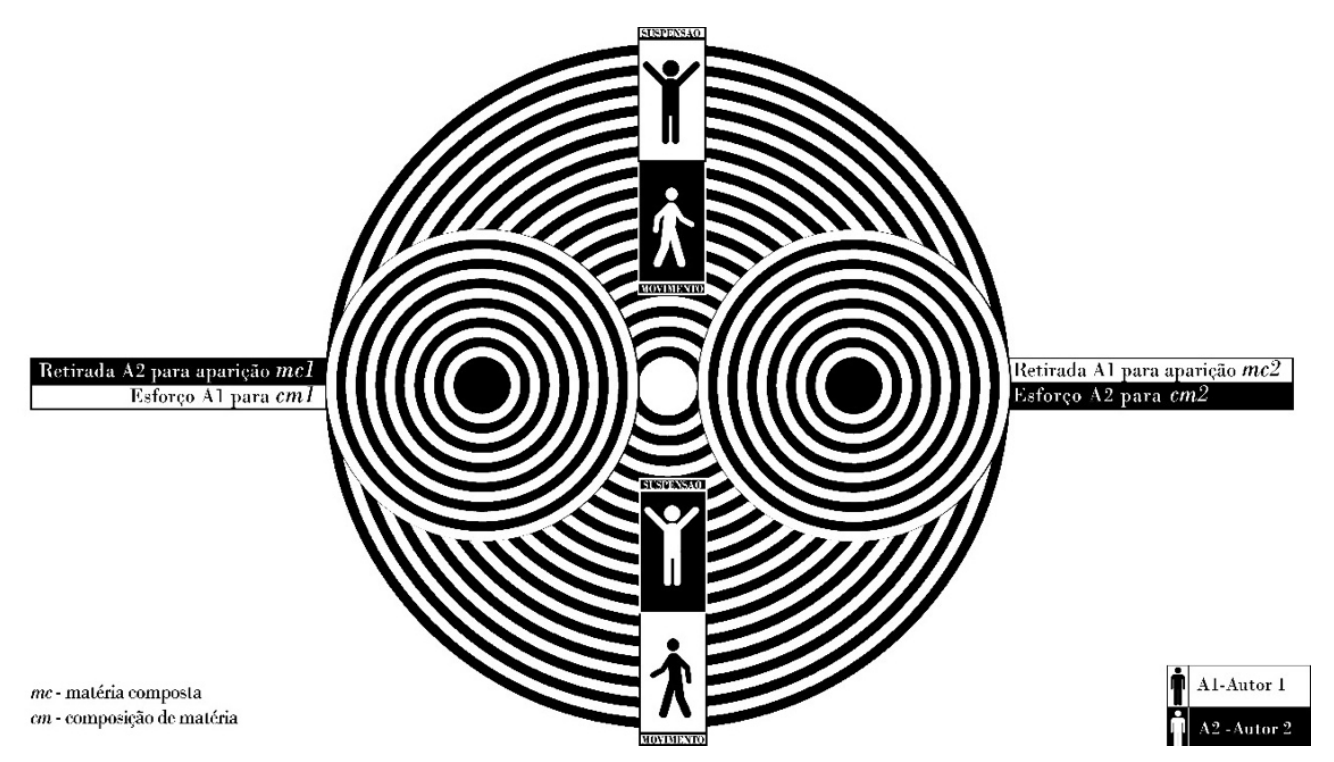

Figura 8. Máquina Colaborativa 1. João Lucas 
VIS

Revista do Programa de Pós-graduação em Arte da UnB

Mas um terceiro vetor ou linha de fuga mantém instável esta implicação dos criadores na direção da obra. Se A1 caminha na direção de A2 (se ele se retira para que apareça o pensamento de A2 e se, num movimento de refluxo de tal abertura, afirma o seu próprio pensamento), caminha igualmente em direção à obra (se retira para que apareça o pensamento de A2 e se afirma no seu próprio pensamento). De modo idêntico se implica A2 com A1 (se retirando perante o pensamento de A1 e reagindo reflexivamente no seu próprio pensamento), dirigindo-se simultaneamente à obra (se abrindo à imanência da matéria trazida por A1 e se projetando no esculpir da sua própria invenção).

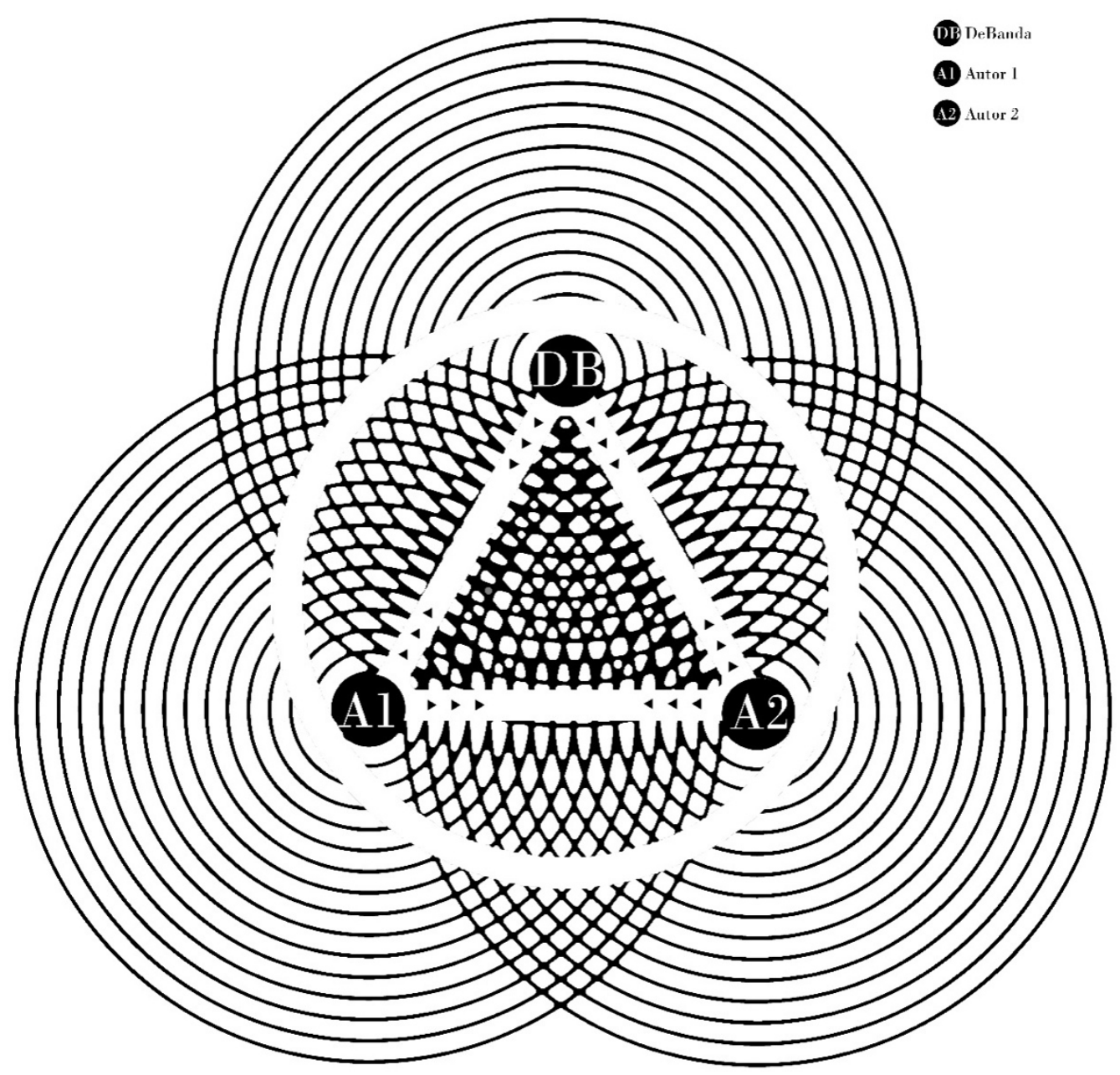

Figura 9. Máquina Colaborativa 2. João Lucas

Esta rede trifásica de intersecções de figuras de consciência envolve o trânsito de sentidos e de conceitos em implicação infinita, circulando incessante167 
mente nos três vetores, permanentemente realimentados e projetados em novas transfigurações. Além disso, sendo a obra depositária dos perceptos e afetos que vão edificando o seu plano de composição, nesta polarização tripartida do processo criativo deflagram momentos de intensidade, a partir dos quais os sentidos reordenam seus traços intensivos, se realinham ou corrigem suas órbitas, reforçam ou retificam sua direção; há uma multiplicidade de experiências estéticas fragmentárias (virtuais ou atuais) na captura da expressão do outro, e nelas a expressão do outro se oferece na produção dos seus efeitos de presença, dos quais derivam e posicionam os sentidos que os envolvem e desse modo reverberam nos afetos e perceptos do plano de composição. A máquina colaborativa cria, assim, uma espécie de câmera eletromagnética triangular na qual reagem entre si todos os fatores de condicionamento inventivo e da qual procede uma identificação progressiva e recíproca entre os autores e a sua obra.

\section{A máquina performativa}

Entre o orgânico e o maquinal, o afeto e a razão, o suor e o som, a artesania tecnológica e a voz cantada, seguiu-se o confronto com o mundo por intermédio de uma máquina performativa, calibrada para amalgamar esses corpos sonoros embriagados de fracasso e desejo - numa relação que se assemelha, por vezes, à do velho Geppetto com Pinocchio. Assim como Pinocchio sonha em ser um menino, a máquina SerBanda clama e carbura pela simbiose com um ser humano e, ao ser acoplada ao corpo do ator, atualiza o seu desejo germinando inicialmente DeBanda - narrador, mensageiro e Corifeu - e depois suas derivações: Demais, Demenos e Ella, além das imponderáveis maquinações que o contato enseja e a maquinaria permite. 
VIS

Revista do Programa de Pós-graduação em Arte da UnB

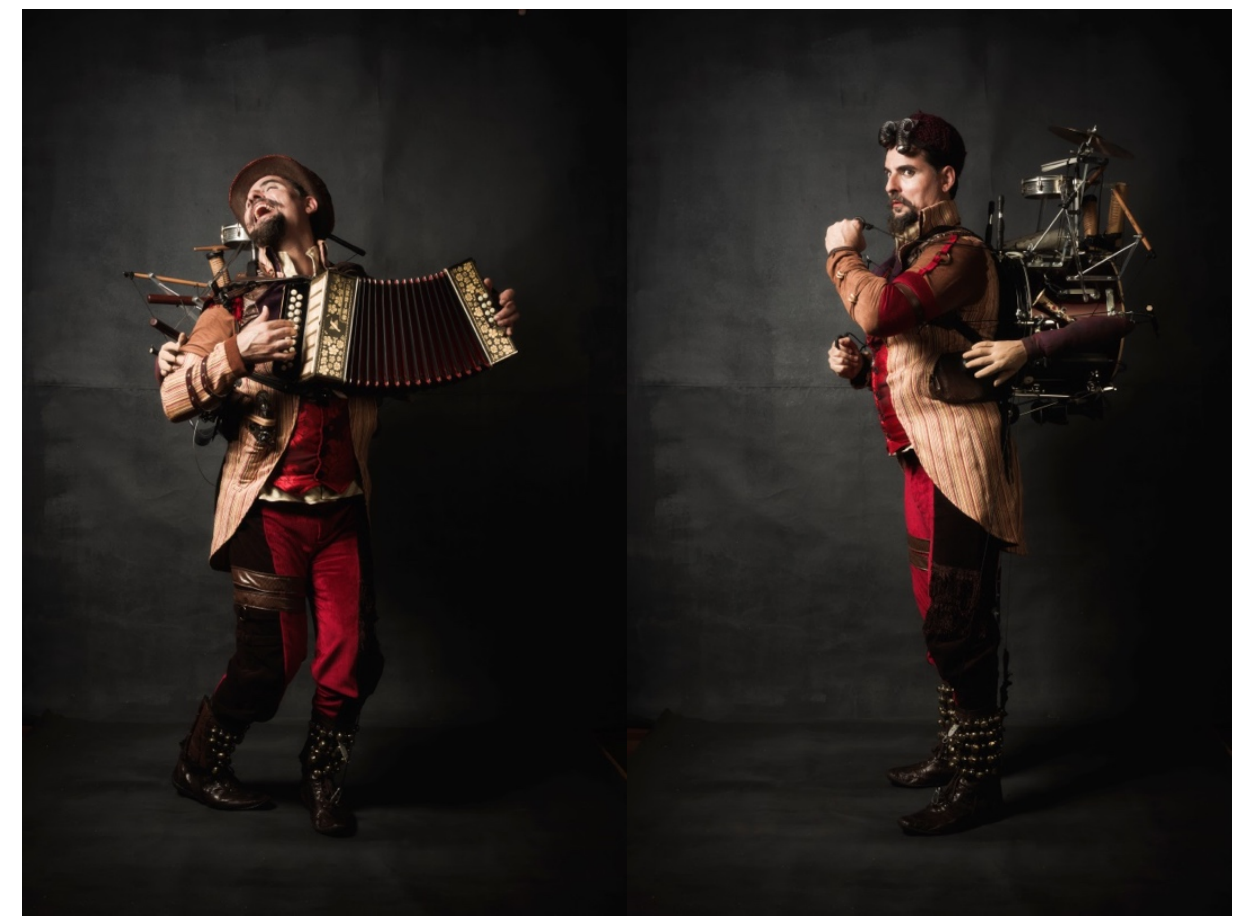

DeBanda - Figura $10^{5}$

Demenos - Figura 11

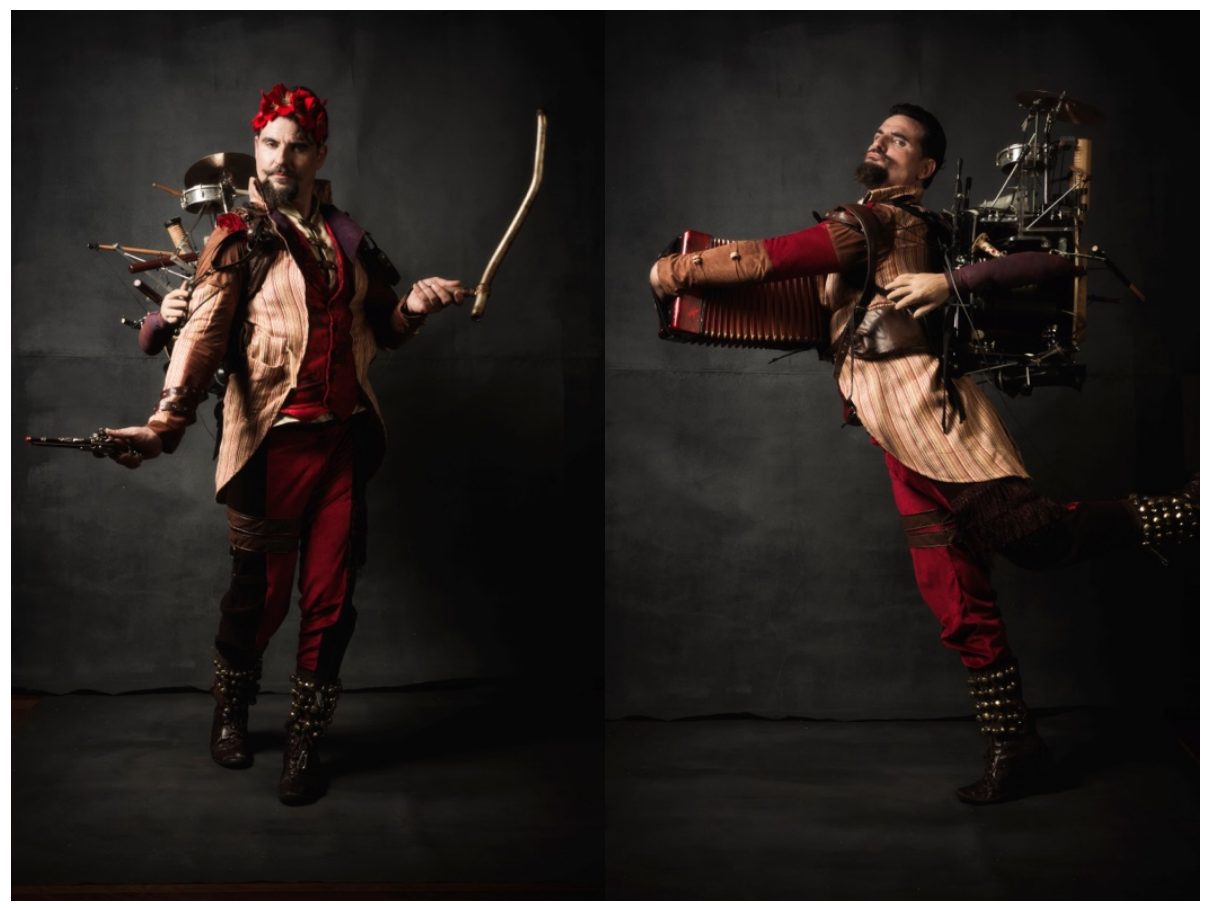

Ella - Figura 12

Demais - Figura 13

${ }^{5}$ Fotos 10 à 15 de Diego Bresani. 
A gama sensorial produzida pela máquina performativa é conflituosa. $\mathrm{O}$ corpo multiplica-se em carisma, dimensão, variedade timbrica e possibilidades de produção sonora em concomitância. No entanto, esse novo corpo adquiriu uma tonelagem hostil, seus movimentos agora apresentam extensões limitadas pelas cordas, sua capacidade fono-respiratória sofre uma redução motivada por conexões que travam a mobilidade das costelas e do abdômen. Os equilíbrios emocional e espacial são igualmente alterados: a componente humana é exposta à insegurança, arriscando a ineficácia e comprometendo a vitalidade. A componente maquínica adentra limites impensáveis, os dois se lesionam, em atritos intempestivos - imbróglios imprevistos para os quais não se vislumbram saídas em manuais ou tutoriais. Como extrapolar os aparentes limites manifestados por estes corpos em colaboração? Como transmutar a dor física em prazer inevitável? Na prática, como acionar a máquina performativa narrando uma história, tocando 23 instrumentos, cantando o tempo todo, dançando e, sobretudo interpretando?

O tempo do processo incubatório impeliu a dilatação. Para contornar a impotência instaurada, todo o mapeamento, foco, intenções, qualidades de movimento e timbres utilizados para o canto e orquestração de cada uma das personagens se afigurava insuficiente. Que tipologia performativa afirmava a nossa máquina? Uma opereta de um homem só embalada por um Don Quixote de meia tigela? O que propúnhamos com está ousadia infinda? Brincar com os limites da vida, da morte e da criação? Como Dr. Vitor Frankenstein que promove uma espécie de coisa a partir de fragmentos de outros corpos inanimados, o resultado atingido não primou pela afabilidade. Desde o primeiro momento, assinalado pela epifania na qual se virtualizou a máquina musical em 2015, DeBanda foi - e vem - se tornando coisa desde então. O que era semente clamou pelo cultivo obstinado desses corpos para brotar, para além de toda a maquinaria plausível e de toda a funcionalidade expectável.

Consumado este processo de abrolhamento intermediário, DeBanda desgarrou-se e libertou suas juntas e roladanas em Singapura em 2017. Depois, circulou pelo Brasil (Estados de Goiás e Mato Grosso do Sul), Paraguai, Argentina, 
VIS

Revista do Programa de Pós-graduação em Arte da UnB

Uruguai, Chile e Peru em 2018. O périplo aventuroso pela América do Sul se deu em pequenos dormitórios sobre rodas em meio a altitudes radicais e ambientes de geleiras, desertos e florestas.

DeBanda perambulou por cidades de pequeno porte - com até 100 mil habitantes -, realizando 33 performances em locais públicos, como praças, parques, escolas e ruas, em oficinas mecânicas e em átrios de igrejas, motivadas pelo desejo de diálogo, de conexão, de experiência. Que mais se faz necessário para se aproximar do corpo sem órgãos artaudiano?

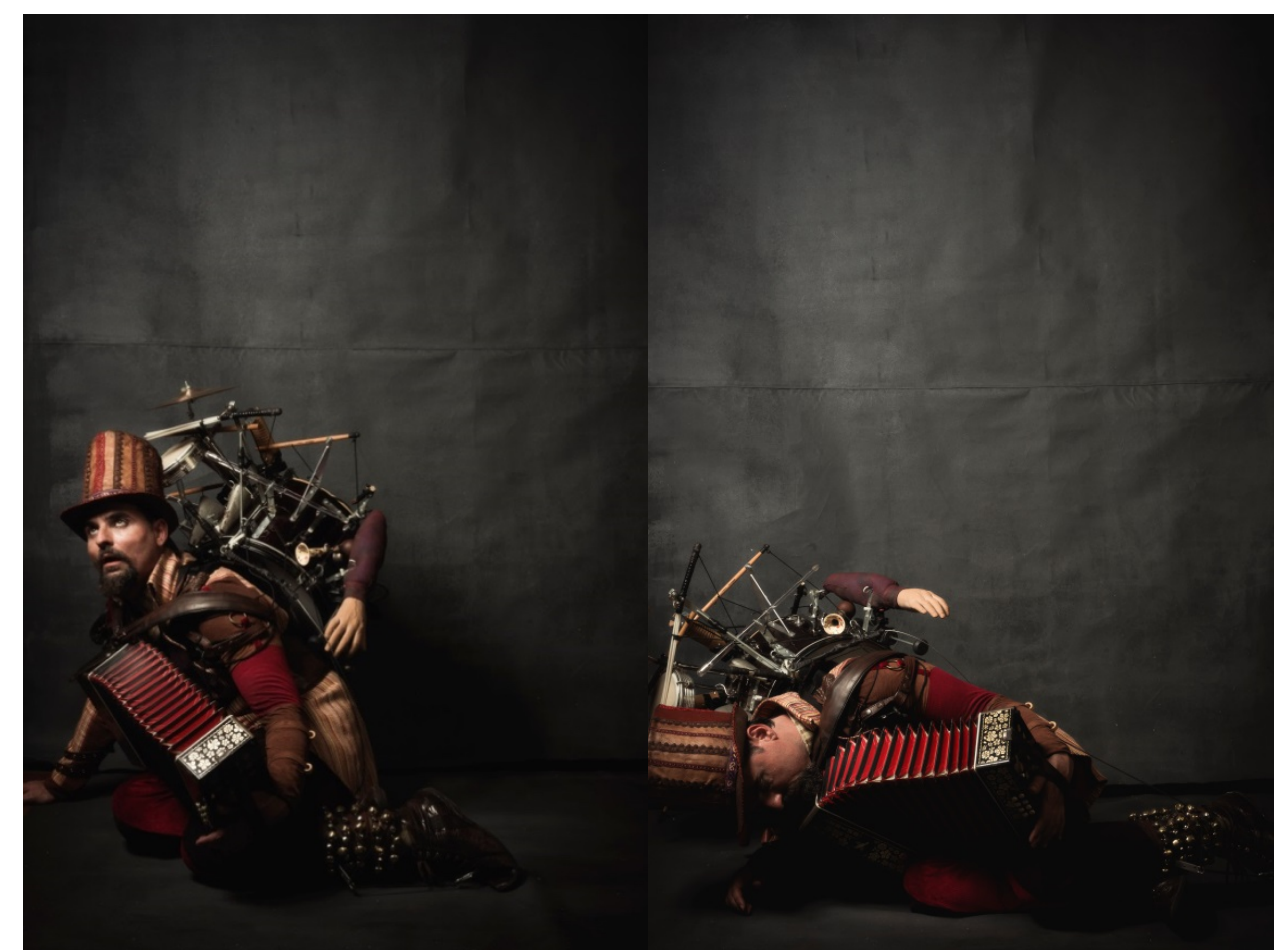

DeBanda - Figura 14

DeBanda - Figura 15

Se conformar com a finitude ou operar com infindo fervor em direção a eternidade? Solidão. Fracasso e desejo são o seu idioma.

\section{Referencias}

AGAMBEM, Giorgio. O que e o contemporâneo e outros ensaios. Trad. Vinicius Nicastro Honesko. Chapecó: Argos, 2009. 
VIS

Revista do Programa de Pós-graduação em Arte da UnB

CALVINO, Italo. As Cosmicómicas. Trad. Ivo Barroso. São Paulo: Schwarcz, 1992.

DELEUZE, Gilles, \& GUATTARI, Felix. Mil Platôs: capitalismo e esquizofrenia, vol. 5. Trad. Peter Pal Pelbart e Janice Caiafa. São Paulo: Editora 34, 1997.

DELEUZE, Gilles, \& GUATTARI, Felix. Mil Platôs - capitalismo e esquizofrenia, vol.1. Trad. Aurélio Costa Neto e Celia Pinto Costa. S. Paulo: Editora 34, 2000.

LÉVINAS, Emmanuel. (2004). Entre nós. Trad. Pergentino Stefano Pivatto (coord.), lvaldo Antonio Kuiava, Jose Nedel, Luiz Pedro Wagner, Marcelo Luiz Pelizolli. Petrópolis: Vozes, 2004. 